\title{
La Revolución Americana y la Haitiana en el hemisferio Americano, 1776-1804
}

\author{
Por Franklin W. Knight ${ }^{\star \star}$
}

\begin{abstract}
Resumen
El siguiente artículo aborda las revoluciones que entre 1776 y 1804 experimentó el mundo atlántico, señalando cómo se desarrollaron en cada proceso conceptos como la democracia, la igualdad y la participación política. Se examina además la influencia del siglo de las luces en estos movimientos y se hace especial énfasis en la Revolución de Haití, resaltando cómo esta hizo de la libertad un derecho fundamental, convirtiéndose así en el suceso político y social más significativo para el Caribe durante esta época, e influenciando los procesos libertarios que se llevaron a cabo en América Latina.
\end{abstract}

Palabras claves: Revolución americana, Haití, independencia, llustración, colonia.

\begin{abstract}
The following article discusses the revolutions that between 1776 and 1804 experienced the Atlantic world, noting how these movements developed concepts such as democracy, equality and political participation. It also examines the influence of the Enlightenment in these revolutions, especially in Haiti, where freedom was considered a fundamental right, thus becoming the political and social event more meaningful for the Caribbean during this time, and influencing the Latin American liberation processes.
\end{abstract}

Keywords: American Revolution, Haiti, independence, Enlightenment, colony.

Entre 1776 Y 1804 tres grandes revoluciones agitaban el mundo atlántico: la de los Estados Unidos de América entre 1776 y 1783, la de Francia entre 1789 y 1815 y la de Haití entre 1791 y 1804. Las tres son vinculadas por sus ideas novedosas y sus circunstancias políticas.

Todos los cambios políticos posteriores reflejan las ideas generales de esas tres grandes revoluciones. Las guerras de la independencia de América Latina, terminaron en gran parte el Imperio Español americano continental, y empezó la transformación radical del imperio portugués. Estos cambios formaban parte de

\footnotetext{
${ }^{*}$ Artículo tipo 2: de reflexión según Colciencias.

${ }^{* *}$ Profesor de Historia Universidad Johns Hopkins, Baltimore, Maryland, Estados Unidos. Especialista en historia social y económica de Latinoamérica y el Caribe, con énfasis en el periodo colonial. E-mail: fknight@jhu.edu.
} 
esta situación revolucionaria del mundo atlántico. Las deliberaciones en Cádiz en 1812 fueron sin duda una manifestación de este amplio descontento revolucionario, una parte integral de esta larga época de revolución.

Las revoluciones tienen sus raíces en las ideas generales del siglo de las luces. La llustración genera muchas de las ideas revolucionarias del tiempo. Pero es importante contemplar el siglo de las luces no sólo como una experiencia enteramente europea sino una experiencia mucho más generalizada.

En ambos lados del Atlántico nuevas ideas habían agitado a las elites durante más de cien años antes de 1776. Como nos lo ha demostrado la historiadora María Portuondo $(2003,2009)$, la investigación de la novedad tiene una larga tradición en el imperio español.

La edad de la iluminación coincidió con el aumento de las ciencias biológicas, con notables avances en química y física, hasta una profunda alteración en las mentalidades convencionales. Entre 1770 y 1840 una plétora de nuevas invenciones en tecnología de vapor, en las comunicaciones telegráficas y en ingeniería mecánica establecieron las bases para lo que a veces se ha llamado "la edad de la revolución" (Palmer, 1969; Davis, 1975). La tecnología del vapor revolucionó la fabricación de textiles y el transporte de ferrocarril, reduciendo tanto el tiempo como la distancia, e integrando mercados previamente distantes e inaccesibles (Blainey, 1966). La máquina de Eli Whitney contribuyó enormemente a la expansión de la cultura de algodón, especialmente en los Estados Unidos del Sur. Los ferrocarriles dominaron los canales y los vapores rápidamente dejando atrás los barcos de vela. Estos cambios tuvieron un impacto profundo sobre el comercio internacional (Ransom, 1984; Woodruff, 1967; Headrick, 1988). Entre 1776 y 1837 se produjeron cambios políticos, sociales y económicos significativos en todo el Caribe en particular y entre las Américas en general, cambios que transformarían para siempre la historia del mundo.

Esta presentación no va a revisar este panorama amplio e interconectado de cambios, sino simplemente a examinar las principales ideas políticas, sociales e intelectuales que eran más prevalentes en toda la región. Las tres principales revoluciones pusieron de relieve muchas de estas ideas.

La Revolución Americana entre 1776-83 rompió la cohesión del imperio británico en Norteamérica, estableciendo la precedencia de construir un estado nuevo. Fue en realidad una forma de ingeniería política. $Y$ los americanos escribieron una Constitución que representó un contrato explícito entre el gobierno y los ciudadanos que se convirtió en el modelo imitado en Francia y en todo el hemisferio occidental en las décadas posteriores (Wood, 1992).

La revolución norteamericana fue puramente política. No fue una revolución democrática. De hecho, el historiador Jack P. Greene (2000, pp.93-102) sugiere que la revolución norteamericana realmente no era revolucionaria. Se diseñó un nuevo Estado político que hizo posible la construcción deliberada de nuevas 
entidades políticas sin la necesidad de una dinastía o de la intervención divina. Sin embargo, Estados Unidos no trató de redistribuir el poder político. Tampoco buscaba una representación democrática. Tenía una visión estrecha del "hombre" cuando declaró "todos los hombres son iguales" Este concepto de hombre se limitaba a los hombres de linajes anglosajones de piel blanca, protestantes y el inconfundible burgués, precisamente el tipo de personas que habían controlado el poder político colonial por todo el imperio británico.

Lo importante es que la revolución americana no alteró la base social del poder político. Pero la franquicia electoral no era la única área en la que la Constitución de los Estados Unidos sería algo restrictiva. La creación de un colegio electoral, o de la representación proporcional (que existe hasta hoy), fue un flagrante intento de mantener el poder político entre las principales familias de la costa Atlántica entre Massachusetts y Carolina del Sur. Este colegio electoral hizo una burla de la idea de que cada voto fue igual. El concepto del Estado no fue ampliado para incluir los de abajo. Representaba un estado donde los mayores beneficios pertenecían a una minoría privilegiada. La revolución norteamericana no intentaba cambiar la base fundamental del poder político. Simplemente trataba de cambiar la estructura política superficial (Wodd, 1998), y este cambio en 1776 fue muy revolucionario.

Comparado con la estructura política caótica del imperio británico durante el siglo XVIII, Francia tenía un sistema político mucho más centralizado. El ejercicio de representación y la negociación política habían estado inactivos durante casi dos siglos, pero no se olvidaban totalmente la historia y las tradiciones administrativas. Los Estamentos Generales (las Cortes o Estates General) aún reflejaban la desigualdad básica de una sociedad feudal en la que los privilegios de los nobles y del clero fueron manifestados y aceptados. El Tercer Estamento de Comunes aún más numeroso no tenía la influencia política de los otros dos, pero inmediatamente al llegar a Versalles en 1789 asumió el control de las actividades.

La Revolución Francesa entre 1789 y 1815 fue un intento más ambicioso en el cambio político que lo que ocurrió en el ejemplo estadounidense. En Francia se estableció la ciudadanía como un derecho fundamental y esta declaración debilitó seriamente la atracción de la monarquía. La Revolución Francesa desencadenó el nacionalismo como una fuerza potente centrípeta en todo el continente europeo. El concepto de la nación presentado por la Revolución Francesa representa un avance significativo en la idea de la democracia y la inclusión política.

Este sentido político mucho más complejo que el caso estadounidense, y el intento por eliminar las diferencias de geografía, riqueza y condición social, implicaba hasta cierto punto en la noción de estamentos un intento igualitario de reestructuración política en el que los derechos de voto fueran iguales tanto en los estamentos (Estates General) como después en la Asamblea Nacional, donde la soberanía fue reconocida en términos generales. En este modo la República francesa sería mucho más republicana que la República declarada por los revolucionarios en Filadelfia en 1776. 
Si bien la nobleza y el clero conservaban su homogeneidad de bienes raíces antiguas en las elecciones de 1789, el tercer Estamento se había convertido en un grupo muy heterogéneo, en el que fueron alojados miembros del clero y de la nobleza. Además de los cambios sociales nacionales, la creación de un imperio francés en ultramar había aumentado los problemas políticos de la representación en 1789 y complicado la Revolución Francesa.

Las divisiones básicas de la sociedad francesa tuvieron su origen en las divisiones de clase socioeconómica. Los lemas populares generados por la revolución -la libertad, la igualdad, la fraternidad y los derechos del hombre - no expresaban sentimientos igualmente aplicables o comúnmente entendidos en la metrópoli y en las colonias de ultramar (Curtin, 1950, pp. 157-175).

En Francia los lemas representaban un grito general para la inclusión política de todos los adultos que buscaban la representación política. En las colonias los lemas tuvieron una resonancia más específica. De hecho, a través de los representantes de la Revolución Francesa, no sólo en los Estamentos Generales sino más tarde en la Asamblea Nacional, no se entendería cómo un solo idioma podría interpretarse en tantas formas diferentes, acentuando la diferencia entre metrópoli y colonias (Schama, 1989; Gershoy, 1960; Soboul, 1989; Salvemini, 1954).

La confusión lingüística salió de dos fuentes. En primer lugar, los informes de reclamaciones (cahiers de doléances) de las colonias representaban por abrumadora mayoría no las opiniones de una muestra representativa de la población, sino simplemente las de los propietarios de plantaciones o de una pequeña minoría tanto de ricos como de comerciantes, muchos de los cuales eran residentes en Francia. La confusión lingüística representa dos conceptos distintos del francés: una visión nacional y una visión imperial. Además, como los franceses averiguarían eventualmente, la colonia de Saint-Domingue fue bastante compleja geográficamente y los ricos, expatriados plantadores de los Llanos del Norte eran una minoría distinta. Los intereses económicos y las preocupaciones políticas de los habitantes del centro y del sur de la colonia eran muy diferentes.

En segundo lugar, los lemas ilustran la influencia del pensamiento local sobre la revolución. Cada segmento social de la población colonial libre aceptaba los lemas generales de la revolución metropolitana para ganar aceptación en Francia, pero luego particularizaba sólo esas porciones aplicadas a sus causas individuales. Los Grands Blancs vieron los derechos del hombre como los derechos y privilegios del hombre burgués, como hicieron Thomas Jefferson y los otros autores de la independencia norteamericana en Filadelfia en 1776. Por otra parte, los Grands Blancs aceptaban la libertad no como un asunto individual sino como una mayor autonomía colonial, especialmente en aspectos del comercio antillano.

También los Grands Blancs esperaban que la metrópoli pudiera autorizar el libre comercio, por lo tanto, debilitando los efectos restrictivos del comercio 
monopolizador de la madre patria. Los Petits Blancs, los representantes dominantes de la provincia occidental, deseaban la igualdad, es decir, una ciudadanía activa para cada persona blanca, no sólo los ricos propietarios, y deseaban menos control administrativo sobre las colonias. Entre ellos también se destacaba una curiosa fraternidad basada en la blancura accidental de color de piel que pensaban ser esencialmente francés.

Los Gens de couleur también querían igualdad y fraternidad, pero basaban su reclamación sobre una igualdad de todas las personas libres independientemente del color de piel, desde que - aún más que los petits blancs - ya se cumplieron todos los otros requisitos de la ciudadanía activa.

Los libres -blancos y de color- representaban la minoría de la población de la colonia, alrededor de 20 por ciento de los habitantes. La gran mayoría fueron esclavizados. Los esclavos no formaron parte de la discusión inicial. Pero de sus acciones posteriores se manifestaba claramente su preferencia por la libertad y además tenían sus propias ideas revolucionarias sobre la reorganización económica. No fue la libertad de los blancos. La suya fue una libertad personal que potencialmente socavaba su relación con sus dueños y al sistema convencional de plantaciones que ponía en peligro la riqueza de un número considerable de los que ya estaban libres (Ott, 1973; Knight, 2000, pp. 103-115; 2005, pp. 391-416).

Tanto en Francia como en sus colonias Caribeñas el curso de la revolución formó un paralelo curioso. En Francia, como en la colonia de Santo-Domingo Francés y las otras colonias francesas, el curso de la revolución comenzó con la elección de los estamentos generales a Versalles en el año auspicioso de 1789. Inmediatamente comenzó un conflicto sobre la forma de representación que dividió a los de la metrópoli y los de las colonias.

Los de las diversas colonias de ultramar que asumieron o aspiraban a ser franceses y a participar en las deliberaciones, no compartieron realmente la historia y tradición de los de la metrópoli. En muchos sentidos eran hombres nuevos creados por un nuevo tipo de sociedad: la sociedad ultramar de esclavos de plantación.

Para los franceses fue una experiencia muy distinta de la los plantadores y propietarios de esclavos en el Caribe inglés. En Jamaica el señor Edward Long era al mismo tiempo un miembro influyente y rico de la sociedad inglesa y un distinguido de la sociedad y política de la colonia. Bryan Edwards fue por muchos años en el servicio de la legislatura de Jamaica y después de 1796 un legítimo miembro del Parlamento británico (Brathwaite, 1971, pp.73-79; Goveia, 1956, pp. 53-63; Billington, 1980, p. 22).

La estructura política francesa era muy diferente a la de las colonias ultramarinas y faltaba representación en la cortes. La revolución francesa empezó bien para los representantes coloniales cuando los estamentos generales se convirtieron en 
Asamblea Nacional en mayo de 1789 y la Asamblea Nacional proclamaba a Francia como una República en septiembre de 1792. En Francia "la historia posterior de la rebelión armada revela una unidad aparentemente irresistible hacia un ejecutivo central, fuerte. El Comité de Seguridad Pública de doce hombres de Robespierre (1793-94), dieron paso a un Directorio de cinco hombres (1795-99), luego a un consulado de tres hombres, seguida por la designación de Napoleón como primer cónsul en 1799 y finalmente a la coronación de Napoleón como emperador en 1804" escribió el historiador James Billington ( 1980, p. 22).

En las colonias el mismo movimiento es discernible con una diferencia importante, al menos en la colonia de Santo-Domingo. La consolidación del poder durante el período de la rebelión armada se concentraba hacia los de color y terminó en manos de los esclavos y los ex-esclavos o sus descendientes.

La estructura política de la metrópoli y de la colonia se partió en dos aspectos fundamentales. La política de la metrópoli se trasladó hacia una estructura jerárquica cada vez más estrecha. El poder del estado se trasladó de una burocracia dinástica a una administración nacional en una nueva República antes de volver a concentrarse bajo Napoleón Bonaparte. En las colonias, especialmente en Santo-Domingo, la autoridad se concentraba más y más hacia abajo a la mayoría de la población. En segundo lugar, la metrópoli hizo una política de exclusión eliminando amigos de la familia real y emigrados mientras se buscaba ampliar la base de poder así como los privilegios de la burguesía y los comunes. En las colonias por otro lado, una vez que la rebelión de esclavos estalló en agosto de 1791 la búsqueda fue para una nivelación o la eliminación de todas las distinciones de clase social y del poder político, aunque esto no era una idea universalmente aceptada al principio de la revolución. Claramente, como señala el historiador Laurent Dubois (2004a, 2004b), los nuevos ciudadanos de las colonias del Caribe francés ampliaron enormemente la concepción política de la ilustración por los derechos extendidos a un grupo de individuos cuya inclusión había ampliado enormemente la idea convencional de los derechos universales.

La revolución haitiana creó el segundo Estado independiente en las Américas y la primera sociedad completamente libre en cualquier área donde las sociedades de la esclavitud ya habían tomado raíz. Era una concepción radical de la idea de libertad. Haití declaró la libertad como un derecho humano fundamental y al hacerlo radicalmente cambió las ideas acerca del hombre y de la sociedad en todo el mundo Atlántico (Landers, 2010, pp.55-94).

Haití, por supuesto, representa el cambio político más revolucionario en el mundo en ese momento. Aprovechando la iniciativa después de la llamada de los estamentos generales en 1788, los colonos libres de Santo Domingo Francés blancos, así como de color - supusieron que compartían la identidad política de sus compañeros metropolitanos y empezaron inmediatamente a compilar sus cahiers de doléances y seleccionaron con entusiasmo entre sí los delegados para asistir el evento de Versalles. La consecuencia inmediata fue una explosiva 
situación política colonial que desarrolló rápidamente una vida propia dentro de la escena rápidamente cambiante de la revolución francesa doméstica. De repente definir la ciudadanía francesa asumió proporciones conflictivas. En 1794 el 80\% de la población en las colonias de Santo Domingo (junto con las de la Martinica y Guadalupe) ganó la libertad jurídica de la Asamblea Nacional francesa gracias a las sublevaciones de los esclavos, aunque sólo temporalmente. Revertir la emancipación legal resultada imposible en Santo Domingo y en 1804 JeanJacques Dessalines declara la independencia de Haití. La independencia haitiana representaba un logro monumental (Dubois, 1998). La Constitución declaró a todas las personas igualmente libres, una declaración que tendría profundas repercusiones políticas y sociales a lo largo de la costa atlántica de Bangor, Maine y Buenos Aires, Argentina.

La Declaración de la independencia política en los Estados Unidos así como más tarde entre zonas españolas y portuguesas de América no fue nada más que una transferencia de una administración política de la metrópoli y sus representantes a las antiguas colonias, mientras invirtió ese poder en las clases propietarias y sus representantes masculinos. No hubo ninguna revolución social; y ningún desafío a las élites de las no elites. Cuando la declaración norteamericana en 1776 se refirió a la igualdad de todos los hombres se suponía que se incluyó solo los blancos de propiedad. En resumen, la independencia política en los Estados Unidos y los nuevos estados de los imperios españoles y portugueses no resultaban en sociedades verdaderamente democráticas.

Fue precisamente el logro significativo en Haití. La independencia de Haití entregó el poder político inmediatamente a todo el mundo en el Estado con la igualdad legal de sexo, educación, raza, color, riqueza o de ocupación. Fue una gran revolución política y social. La eliminación de los privilegios sociales así como la abolición permanente de la esclavitud representaba una temible perspectiva a todos los esclavistas a lo largo de las Américas, pero fue la única manera lograr el éxito del nuevo Estado.

Después de la declaración del estado de Haití libre en 1804, la antigua institución de siglos de la esclavitud americana comenzó a desintegrarse. No era una desaparición rápida pero fue una desintegración inexorable condicionada por el territorio, el tiempo y las circunstancias actuales. Los británicos abolieron su comercio transatlántico de esclavos en 1807 y a partir de entonces iniciaron la persecución sistemática de los que seguían comerciando con cargas humanas a través del Atlántico. Este comercio transatlántico, sin embargo, persistiría hasta la década de 1870.

La institución de la esclavitud fue abolida por etapas a través de las Américas empezando en 1791 cuando los esclavos del Plain du Nord en Santo Domingo Francés declararon su libertad y terminando en el año de 1888 cuando los brasileños abolieron su sistema. El fracaso de Francia en restaurar la esclavitud en su colonia más importante - la de Santo Domingo- persuadió a Napoleón a 
vender el inmenso territorio de Luisiana a los Estados Unidos en 1803 y reducir enormemente su interés en un imperio americano durante varias décadas.

Las colonias españolas continentales ganaron su independencia mediante la guerra. En 1819 España vendió Florida a los Estados Unidos, dándole el control total del área por debajo de los grandes lagos y al este del río Mississippi. Esta consolidación territorial económica proporcionaría la base para un espíritu irreprimible que después se llamó "Manifest Destiny "(Destino manifiesto) y que finalmente culminó en los cuarenta y ocho estados contiguos que extienden desde el Océano Atlántico al Océano Pacífico.

Para el Caribe el establecimiento del Estado libre de Haití representó el acontecimiento político más significativo del período. Pero también se estaban produciendo otros cambios políticos importantes. La importancia política y económica de Cuba dentro del reducido Imperio Español americano a principios del siglo XIX coincidió con la primera revolución agrícola que se estaba produciendo en esta isla. (Esto constituye una expansión de las revoluciones del azúcar en el Caribe que habían comenzado en Barbados en la mitad del siglo XVII). Esta manifestación tardía de la revolución del azúcar simultáneamente tuvo lugar en Puerto Rico, Trinidad y Guyana británica y resultó de la destrucción de la producción azucarera en Haití y la migración de sus habitantes.

En el Caribe británico una rivalidad se desarrolló entre las primeras colonias como Barbados, Sta. Kits, Nevéis, Antigua y Jamaica (capturada por los españoles en 1655) y las colonias recientemente capturadas - La Granada, Dominica, San Vicente - después de la guerra de los siete años (1756-1763) o durante las guerras de la revolución francesa - Santa Lucía, Trinidad, Demerara y Berbice. "Las Antillas británicas a mediados del siglo XIX," escribieron los historiadores John Parry y Philip Sherlock (1971, p. 205), "formaron un museo rico y variado de antiguas formas constitucionales y administrativas". Los habitantes de las primeras colonias inglesas de las Antillas pensaban que sus sociedades eran microcosmos de la sociedad inglesa y que sus asambleas representativas reflejaban la posición política del Parlamento británico. Nada podría ser más alejado de la realidad, ya que por 1800 las colonias caribeñas no eran sociedades inglesas sino comunidades artificialmente construidas de plantaciones con esclavos. Aunque después de 1797 la corona británica administraba directamente las colonias caribeñas recién adquiridas, se permitían la continuación de la mayoría de las leyes y formas administrativas de los holandeses en el caso de Essequibo, Berbice y Demerara y de los españoles en el caso de Trinidad. Después de 1830 la así llamada "monarquía de julio" en Francia, siguiendo la práctica de los haitianos después de 1804, introdujo el concepto de igualdad ante la ley, y lo aplicó a sus colonias de ultramar.

En 1834 las Antillas francesas (Martinica y Guadalupe) iniciaron un periodo de asambleas localmente elegidas en una franquicia restringida - más amplia que en las Antillas británicas - que fueron seguidas en 1848 por la elección directa de representantes del Caribe francés a la Asamblea Nacional. 
A nivel de política local en todo el Caribe de habla inglesa, una clase relativamente pequeña controlaba la administración local y creó leyes para proteger sus intereses económicos. En las Antillas británicas los poderosos eran una minoría minúscula de la población adulta, aunque antes de 1833 la franquicia gradualmente fue ampliada para incluir algunas personas ricas personas de color. Una Orden del Consejo del gobierno británico de 1828 abolió toda distinción civil y militar basada en raza o color y así extendía la igualdad entre los varones adultos en sus territorios directamente controlados. La asamblea de Jamaica siguió en 1830 y Barbados lo hizo el año siguiente. Para 1834 todos los hombres adultos de propiedad, incluyendo los judíos, podían votar en todos los territorios con asambleas constitucionales en todo el Caribe de habla inglesa ${ }^{1}$.

No se puede sobreestimar fácilmente el significado a largo plazo de este incipiente pluralismo político Antillano. Al abrir la franquicia a todos los varones adultos con propiedad antes de la abolición de la esclavitud, los ingleses inadvertidamente establecieron el principio de igualdad ante la ley y eliminaron ese aspecto de los derechos civiles de la lista de quejas que requirió atención en los años después de la plena emancipación de esclavos en 1838. Esto no significa que la cuestión perdió su vitalidad e importancia sino simplemente que perdió su primacía urgente.

En el Caribe británico el sector político surgió como método no sólo de movilidad ascendente sino de pluralismo político. El acceso político no ocurrió inmediatamente en la ampliación de la franquicia electoral en el Caribe británico. La adquisición de propiedad siguió siendo el obstáculo difícil. La gran mayoría de los varones adultos eran pobres y de color y fueron marginados de la participación política activa hasta el establecimiento del sufragio universal a partir de 1944. La situación jurídica - comparada con la realidad - contribuía a un modelo diferente de la evolución política en el Caribe británico entre mediados del siglo XIX y principios del XX.

La vida política en las Antillas británicas, francesas, Neerlandesas y en Puerto Rico parecía más legalista y constitucional, mientras que parecía más bélica en Cuba, Haití y la República Dominicana. Sin embargo, el Caribe, como otros países de América Latina, no experimentó una política de conflicto racial o formalmente segregacionista que se encontraba en los Estados Unidos de América a lo largo del siglo XIX y hasta mediados del siglo XX.

Es posible colocar las variaciones Caribe y América Latina dentro de la experiencia más generalizada con revoluciones durante los siglos XVIII y XIX. Igual que en Europa, el Caribe y América Latina también luchaban con ideas transformadoras de cambio social, político y económico. Como en Europa, las condiciones locales también afectaban la evolución de las ideas mismas. Las

\footnotetext{
${ }^{1}$ Después de 1834 los judíos ganaron el voto en las Antillas, y el 1858 lo obtuvieron en Gran Bretaña.
} 
ideas principales en la era de la revolución involucraban la transformación de la estructura política del Estado y su relación con sus ciudadanos recién designados.

En el caso de los Estados Unidos de América los ingenieros de la transformación política hicieron hincapié en la defensa de la propiedad privada, incluida la propiedad de los individuos. En su revolución la protección de la propiedad privada fue la principal responsabilidad del Estado, y los propietarios controlaron los principales instrumentos de Gobierno. La franquicia política no se distribuyó democráticamente.

En Francia los objetivos de la revolución necesitaron la distribución del poder político entre los miembros del estamento de comunes y los otros estamentos y el repartimiento de las responsabilidades económicas de la administración entre todos los ciudadanos. Con el país continuamente en guerra fue necesaria una medida de precaución. Teniendo en cuenta que la revolución francesa habla redistribuido el poder político, esta representa una revolución más amplia y democrática que la de los Estados Unidos y su estructura operativa de la República también fue más inclusiva. Sin embargo en Francia definir la ciudadanía se dificultaba con la realidad del imperio de ultramar y las consecuencias ineludibles de la raza, color y origen étnico.

En Haití las ideas originales de la revolución francesa llegaron a ser ampliadas porque al principio la gran mayoría de la población no se consideró elegible para la ciudadanía aunque los esclavos fueron indispensables para cumplir con las tareas de guerra y el desarrollo económico del país. Después de agosto de 1791 este sector, al igual que los miembros del estamento de comunes y de la sans culofte en Francia, asumió la responsabilidad y estableció una república igualitaria en la que se declararon los derechos humanos universales. Por desgracia, Haití no podría mantener ni una república política estable ni el ideal de los derechos humanos universales, pero al menos defendió su libertad.

Las sociedades esclavistas del Caribe del siglo XVIII eran dinámicas con diversas oportunidades de movilidad económica y social. De alguna manera se podría decir que las sociedades caribeñas eran intrínsecamente revolucionarias y la más revolucionaria se encontró en Haití. Su sistema de libres y esclavos, por diversas razones, nunca podría generar y mantener las fisuras sociales mutualmente exclusivas como ocurrió en los Estados Unidos de América. En su lugar, las sociedades caribeñas, como las de los territorios de España y de Portugal manifestaban fisuras sociales algo vinculadas y estas facilitaban un desarrollo social menos conflictivo. De Haití salió ese sentimiento de humanidad y libertad individual que resonaba con Simón Bolívar y otros libertadores de América Latina. Así podemos decir que la independencia de América Latina también tiene sus raíces en la revolución haitiana. 


\section{BIBLIOGRAFÍA}

Blainey, Geoffrey. (1966). The Tyranny of Distance. How Distance Shaped Australia's History. Melbourne: Sun Books.

Billington,James H. (1980) Fire in the Minds of Men. Origins of the Revolutionary Faith. New York: Basic Books. p.22.

Brathwaite,Edward. (1971). The Development of Creole Society in Jamaica, 177011820. Clarendon: Oxford University Press. pp. 73 - 79.

Curtin, Philip D. (1950). "The Rights of Man in Saint-Domingue. 1788-1791". En Hispanic American Historical Review. 30:2. pp. 157-175.

Davis, David Brion. (1975). The Problem of Slavery in the Age of Revolution, 17701823. Ithaca: Prensa Universitaria de Cornell.

Dubois, Laurent. (1998). Les esclaves de la République: I'histoire oubliéee de la premiére emancipation, 1789-1794. Paris: Calman-Lévy.

. (2004). A Colony of Citizens: Revolution and Slave Emancipation in the French Caribbean. Chapel Hill: University of North Carolina Press.

(2004). Avengers of the New World: The Story of the Haitian Revolution. Cambridge: Harvard Press University.

Gershoy, Leo. (1960). The French Revolution, 1789-1799. New York: Holt, Rinehart, Winston.

Goveia Elsa. (1956). A Study on the Historiography of the British West Indies to the end of the Nineteenth Century. México: Instituto Panamericano de Geografía e Historia. pp. 53-63.

Greene Jack P. (2000). "The American Revolution". En The American Historical Review. 105:1. pp. 93-102.

Headrick, D. R. (1988). The Tentacles of Progress. Technology Transfer in the Age of Imperialism. 1850-1940. New York: Oxford University Press.

Knight, Franklin W. (2000). "The Haitian Revolution". En American Historical Review. 105:2. pp.103-115.

. (2005). "The Haitian Revolution and Human Rights". En Journal of the Historical Society. 5:3 . pp.391-416.

Landers Jane G. (2010) Atlantic Creoles in the Age of Revolution. Cambridge: Harvard University Press. pp. 55-94. 
Ott, Thomas. (1973). The Haitian Revolution, 1789-1804. Knoxville: University of Tennessee Press.

Palmer, Robert. R. (1969). The Age of the Democratic Revolutions: A Political History of Europe and America, 1750-1800. Princeton: Prensa universitaria de Princeton.

Parry, J. H. \& Sherlock, Philip. (1971) A Short History of the West Indies. New York: St. Martin's Press. pp. 205.

Portuondo ,María. (2003). "Plantation Factories: Science and Technology in late eighteenth century Cuba". En Technology and Culture. 44:3. pp. 231-257.

(2009) Secret Science: Spanish Cosmography in the New World. Chicago: Prensa universitaria de Chicago.

Ransom, P.J.G.(1984). The Archeology of the Transport Revolution. 1750-1850. London: World's Book.

Salvemini, Gaetano. (1954). The French Revolution, 1788-1792. Translated from the French by I.M Rawson. New York: Holt, Rinehart, Winston.

Schama, Simon. (1989). Citizens. A Chronicle of the French Revolution. New York: Knopf.

Shapiro, Gilbert. \& Markoff, John. (1998). Revolutionary Demands. A Content Analysis of the Cahiers de Doleances of 1789. Stanford: Stanford University Press.

Soboul Albert. (1989). The French Revolution, 1787-1799: from the storming of the Bastille to Napoleon. Translated from the French by Alan Forest and Colin Jones. London: Unwin Hyman.

Wood, Gordon S. (1992). The Radicalism of the American Revolution: How a Revolution Transformed a Monarchical Society into a Democratic One Unlike Any That Had Ever Existed. New York: Knopf.

(1998). The Creation of the American Republic. 1776-1787. Chapel Hill: University of North Carolina Press.

Woodruff, W. (1967). Impact of Western Man. A Study of Europe's Role in the World Economy. 1750-1960.New York: St. Martin's Press.

Recibido: Noviembre 11 de 2010

Aprobado: Mayo 9 de 2011 
